\title{
Using Web Surveys To Determine Audience Characteristics And Product Preferences
}

\author{
Jane Hass Philbrick, Savannah State University (deceased), USA \\ F. Ruth Smith, Savannah State University, USA \\ Barbara Bart, Smith-Barney, USA
}

\begin{abstract}
A web survey is a cost-effective and efficient method to use when measuring the characteristics of an audience and developing or testing new product concepts. This paper reports on the use of a web survey by a start-up media/internet firm, Farmers' Almanac TV. The results indicate that using email to contact respondents from a client list results in data which are of excellent quality and quickly obtained.
\end{abstract}

Keywords: internet research, web survey, internet sampling, web opinion survey, web survey methodology

\section{BACKGROUND}

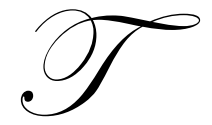

raditional media firms are realizing that consumer and advertising dollars are shifting to the Internet. The continuing growth of online advertising, with a 38\% increase in first quarter 2006 revenue alone, is seen by many as a clear indication that the medium is reaching and engaging its viewers (Interactive Advertising Bureau, 2006). Correspondingly, it is estimated that one third of the monies allocated in the U.S. on marketing research surveys in the near future will be spent on web-based/online surveys (Johnson, 2006).

Over two-thirds of Americans 15 years and older use the internet (Comley, 2003; Johnson, 2006) and almost $60 \%$ of adults in Great Britain report having used the internet (Duffy, Smith, Terhanian, \& Bremer, 2005). The other top nations for country of origin of web sites in 2002 were Germany, Japan, and Canada (Foy, 2004). Clearly, the potential that the worldwide web offers profit and not-for-profit organizations cannot be overstated. Web-based (internet-based) surveys are increasingly used by both practitioners and academics. The recent proliferation of low-cost, proprietary software programs (e.g., ZipSurvey), enable even the novice researcher to design and administer surveys (Hanna, Weinberg, Dant, \& Berger, 2005).

Basically, media businesses have two products to sell: content (to readers and viewers) and audience (to advertisers). The demand for new content has encouraged the growth of new programming and innovative mixtures of television and Internet content. Farmers' Almanac TV is a start-up firm that seeks to provide highly entertaining information and stories about gardening, weather, and other nature-based topics. As such, it delivers its own version of "rural" and "rural want-to-be" users/viewers to its advertisers. But how does a struggling start-up company find out, as inexpensively as possible, what content to sell and what the demographics of their audience are?

After a brief literature review on web survey methodology, this paper will describe the processes undertaken by this start-up media business to identify desired content and characteristics of its audience using inexpensive, proprietary online survey software. We will describe the hybrid survey methodology employed and explain how the information gleaned was used to enhance product offerings and understanding of audience characteristics. The authors hope that this case will serve as a teaching tool for both marketing research and entrepreneurship professors as well as provide useful information to small businesses.

The number of research studies on web survey methodology is enormous (Porter \& Whitcomb, 2003), but the results are often conflicting because much use of the Internet for research purposes occurs in the absence of empirically established methodological guidelines that ensure collection of the best possible information. As has 
been noted by Duffy et al., (2005), studies outlining the advantages and disadvantages of web-based research often fail to distinguish between the types of online research and sampling frames utilized. Many of the disadvantages, such as lower response rates (Healey, Macpherson \& Kuijten, 2005; Roster, Rogers, Albaum \& Klein, 2004), sampling and population bias (Roster et al., 2004; Shannon \& Bradshaw, 2002), and confidentiality (Shannon \& Bradshaw, 2002) are minimized when known customers/client email contact lists are used (Howell \& Smith 2004), as is the case for Farmers' Almanac TV.

The advantages of online surveys include speed of both administration and turnaround (Healey et al., 2005; Johnson, 2006), reduced costs (Healey et al., 2005; Roster et al., 2004; Shannon \& Bradshaw, 2002), and reduced interviewer error (Dillman, 2000; McCullough, 1998). Hanna et al. (2005) found that respondents to online surveys were more thoughtful and, hence, more likely to self-disclose; they tend to provide longer open-ended responses (Schaefer \& Dillman, 1998) and they may be more candid (Meinert et al., 1998; Truell, 2003). There can also be a much higher response rate. Howell and Smith (2004) used a Google-supplied list for their research and obtained a 99 percent response rate. Online research also eliminates coding and tabulating of the responses because they can be directly entered onto a spread sheet when the survey is taken, thus eliminating clerical errors. Interviewer bias present in telephone surveys is also eliminated.

\section{METHODOLOGY}

Unlike the large body of literature on methodologies for mail and telephone survey contact, there is little research describing methodologies for collecting data online. Farmers' Almanac TV used a hybrid survey methodology. They sent an email to their client email list with a request to visit a link provided. There, clients completed a brief questionnaire. The sample universe consisted of individuals who had signed up to receive a free newsletter from FarmersAlmanacTV.com. A random sample of these email addresses was contacted and invited to complete the questionnaire.

Farmers' Almanac TV designed a questionnaire using ZipSurvey and hosted it on the www.zipsurvey.com website (Table 1). The ZipSurvey instrument employs a variety of different question formats to 1) provide feedback about the content of the website so that improvements could be made, which would be beneficial to the user and 2) identify some characteristics of the target audience that could be used to attract potential sponsors/advertisers for both the television program and the website. A third objective was to test the web-based survey methodology itself to determine if it should be used in future studies.

Two samples were selected, one for a pretest and one for the final survey. The pretest sample was obtained by selecting a random sample of 2,000 email addresses from the opt-in data base, as was the post-test sample of 6,000 . No changes were made to the instrument as a result of the pretest, so the final sample size was 8,000.

\section{RESULTS}

The most troublesome aspect of web-based surveys is the sampling methodology employed. Sample selection is important since researchers and decision makers usually seek to generalize findings to the population from which the sample was selected. Broad-based studies inviting responses in an open forum (i.e., Yahoo or Google with banner advertisements inviting participation) are typically criticized as unrepresentative of the general population (Sheehan, 2001). However, sampling from a "closed" population is seen as crucial to successful sampling because every member of the list is a member of the target audience. With this type of "closed" population, a census and both probability and non-probability sampling approachs for selecting participants can be used (Sheehan, 2001).

An example of a closed population is an organizational list, such as members of a faculty, an employee list, or a club's list of members. Shannon and Bradshaw (2002) indicate that to successfully implement electronic surveys, survey professionals usually draw samples from organizational lists containing email addresses. This has the added benefit of assuring that the recipient views the topic as salient, thus increasing the response rate (Sheehan \& McMillan, 1999). Further, it allows for some degree of personalization, which helps maximize response (Heerewegh 2005). 
Table 1: Farmers' Almanac TV Questionnaire on ZipSurvey.com

\begin{tabular}{|c|c|}
\hline Question & Response Choices \\
\hline \multirow{6}{*}{$\begin{array}{l}\text { 1. What types of stories would you like to see more } \\
\text { of on the Farmers' Almanac TV web site } \\
\text { (FarmersAlmanacTV.com)? }\end{array}$} & How to's about gardening, weather farming, natural cures \\
\hline & $\begin{array}{l}\text { Feature stories about the environment, green movement, organic foods, solar } \\
\text { energy, alternative fuels, etc. }\end{array}$ \\
\hline & Product profiles for environmentally friendly tools \\
\hline & $\begin{array}{l}\text { Personalized information (based on geography) for best days for planting, } \\
\text { canning, fishing, etc. }\end{array}$ \\
\hline & $\begin{array}{l}\text { Traditional Farmers' Almanac information like “Wit \& Wisdom,” Recipes, } \\
\text { Weather Forecasts }\end{array}$ \\
\hline & Other (specify) \\
\hline \multirow[t]{4}{*}{ 2. How would you like to view these stories? } & As text \\
\hline & As video \\
\hline & As text and video \\
\hline & Other (specify) \\
\hline \multirow{9}{*}{$\begin{array}{l}\text { 3. What types of stories/information would you like } \\
\text { to read/view in the Farmers' Almanac TV } \\
\text { newsletter? }\end{array}$} & Exclusive Farmers' Almanac Recipes \\
\hline & Exclusive coupons to use at the FarmersAlmanacTV.com store \\
\hline & $\begin{array}{l}\text { Short videos about gardening, farming, natural cures and more that are not } \\
\text { available on the Farmers' Almanac TV web site? }\end{array}$ \\
\hline & Updates abut the television show \\
\hline & Best Days information \\
\hline & Wit \& Wisdom (that is not published on the Farmers' Almanac TV web site) \\
\hline & $\begin{array}{l}\text { Product information from gardening and farming vendors, solar energy } \\
\text { vendors, and others. }\end{array}$ \\
\hline & $\begin{array}{l}\text { Long-range weather forecasts not available on Farmers' Almanac TV Web } \\
\text { site. }\end{array}$ \\
\hline & Other (specify) \\
\hline \multirow[t]{5}{*}{ 4. Where do you live? } & Major city \\
\hline & Small-to-medium sized city \\
\hline & Suburb \\
\hline & Farm \\
\hline & Other (specify) [Most of these responses were rural]. \\
\hline \multirow[t]{4}{*}{ 5. Gardening is: } & A hobby \\
\hline & My job \\
\hline & My job and my hobby \\
\hline & Other (specify) \\
\hline \multirow[t]{4}{*}{ 6. Farming is: } & A hobby \\
\hline & My job \\
\hline & My job and my hobby \\
\hline & Other (specify) \\
\hline $\begin{array}{l}\text { 7. What would you change about the Farmers' } \\
\text { Almanac TV newsletter? }\end{array}$ & Open-end Response \\
\hline \multirow{2}{*}{$\begin{array}{l}\text { 8. Have you ever watched Farmers' Almanac TV } \\
\text { on public television? }\end{array}$} & Yes \\
\hline & No \\
\hline 9. What did you like about it? & Open-end Response \\
\hline 10. What did you not like about it? & Open-end Response \\
\hline \multirow[t]{8}{*}{ 11. Which types of web sites do you regularly visit? } & Gardening web sites \\
\hline & Health or natural cures web sites \\
\hline & Agriculture web sties \\
\hline & Cooking web sites \\
\hline & Alternative energy web sites \\
\hline & Environmentally safe product web sites \\
\hline & Weather web sites \\
\hline & Other (specify) \\
\hline \multirow{2}{*}{$\begin{array}{l}\text { 12. Have you ever shopped at the } \\
\text { FarmersAlmanacTV.com store? }\end{array}$} & Yes \\
\hline & No \\
\hline \multirow{4}{*}{ 13. Why not? } & I never buy anything online. \\
\hline & I didn't see anything that interested me. \\
\hline & I didn't know it existed \\
\hline & Other (specify) \\
\hline
\end{tabular}


Similar to other studies, Farmers' Almanac TV received immediate responses to its online survey (Weible \& Wallace, 1998; Schuldt \& Trotten, 1994). Unfortunately, the Farmers'Almanac executives had signed up for a maximum of 1000 responses, and 800 were received in the first 24 hours. Obviously, the response rate would have been higher if executives at Farmers' Almanac TV had been willing to pay for more responses, and it must be recognized that some would-be respondents were excluded. However, management was satisfied with the information received and, since each sample group provided similar responses, did not feel it necessary to acquire more responses. Once the respondents completed the survey, emails thanking them for their participation were sent.

The responses were collected and a simple report showing the frequency distribution of the responses as well as a list of answers to open-ended questions was available to the executives within minutes of the decision to close the survey. ZipSurvey prepares a summary of the findings at any time during the administration of the survey. Further analysis could be conducted with data analysis packages, such as SPSS, since the data could be exported in a variety of different formats. Although the authors were not given permission to publish the survey results, the results were most helpful to Farmers' Almanac TV and much was learned about the website user and the site's content.

Results of this web-based survey were used to completely redesign the website to provide more links between web and TV content. The site was changed from $95 \%$ video content to $50 \%$ video and $50 \%$ text content. Topics and titles were also changed to address the specific interests of this website audience, including stories about weather, gardening, natural cures, astronomy, and cooking. Comments from the survey suggested a desire for fasterchanging content, so the website is now updated daily and contains content from partner sites so that it is much richer in text and video content. The redesigned website includes a more "hip", or contemporary, blog to address the interests of younger respondents. Figures 1 and 2 show the pre-survey web page and post-survey page.

The Farmers' Almanac TV website now includes an online store for retail purchases. Since over half the survey respondents did not know about the store, the redesigned website has an easy-to-identify call out for the online store on every page. Retail sales have improved.

\section{Figure 1: Pre-Survey Screen Shot}

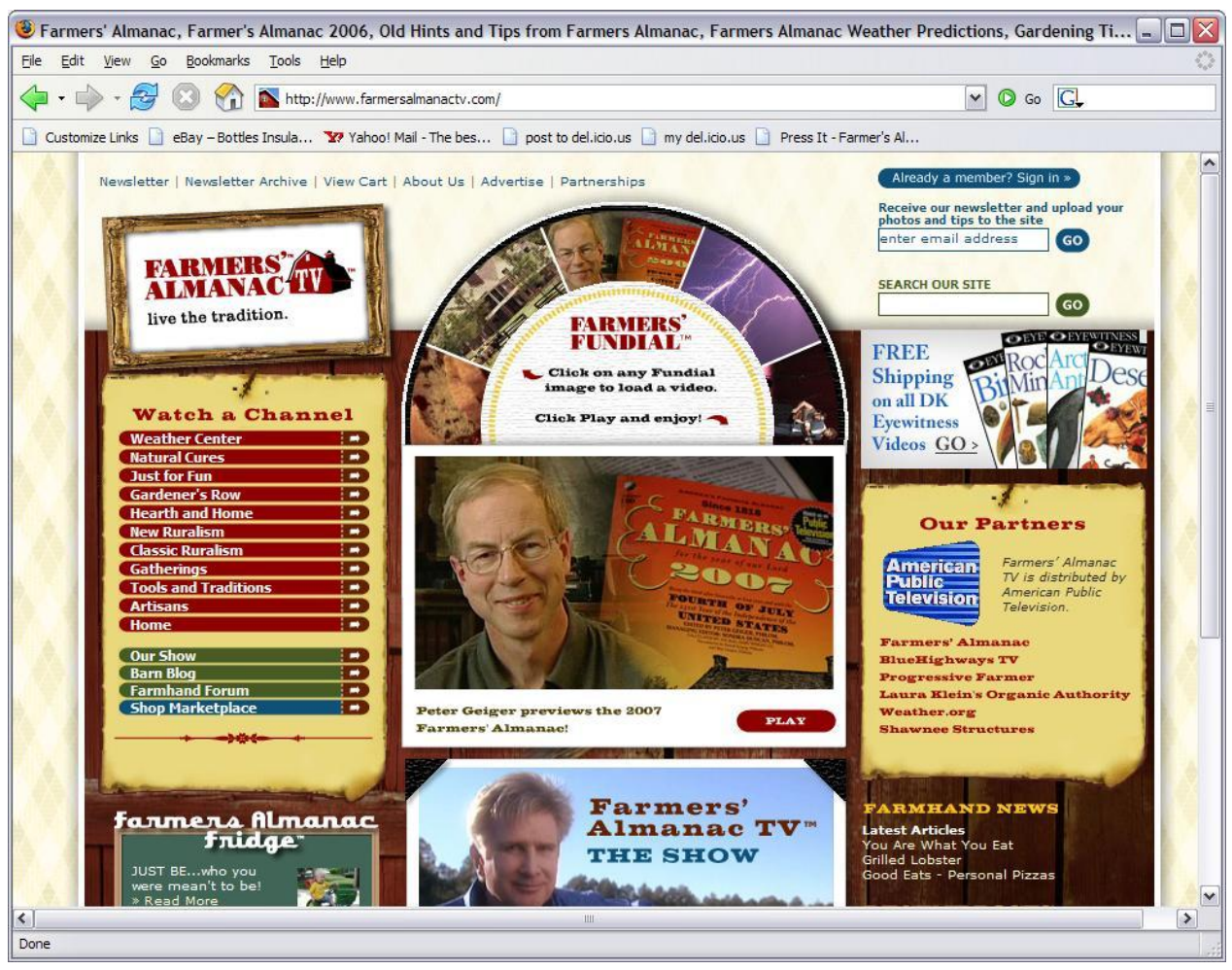




\section{Figure 2: Post-Survey Screen Shot}

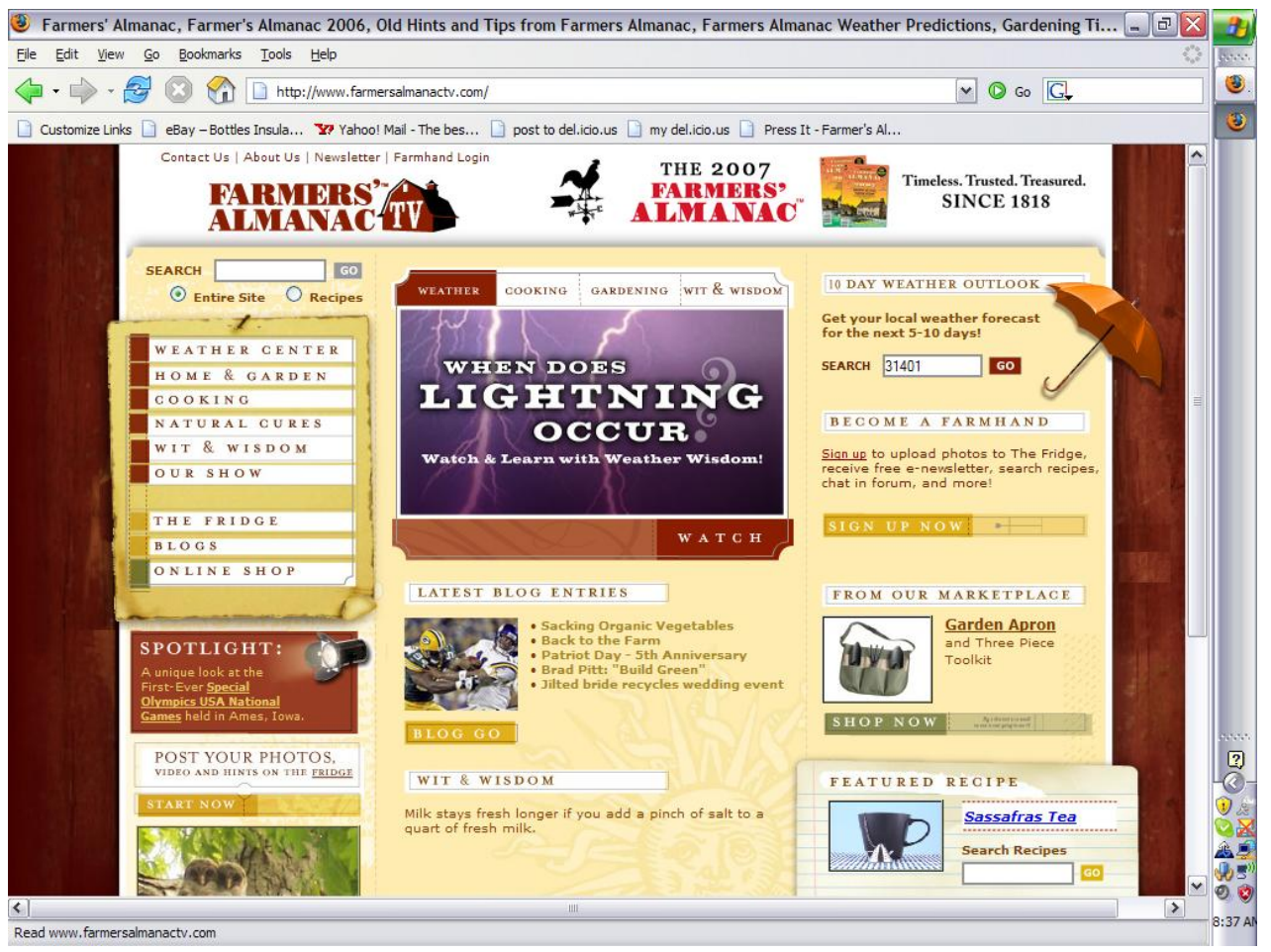

\section{IMPLICATIONS}

A high ranking executive at a global research firm predicts that online panels will be "the basis for the majority of ad-hoc quantitative research around the developed world within the next two to three years" (Johnson, 2006, p.23). There are the obvious benefits of low cost and speed, and researchers have enumerated a host of additional benefits in using web-based surveys. There may be a tendency for respondents to be more candid (Dillman, 2000), to be less inhibited, and to provide long, self-disclosing comments (Foy, 2004; Hanna et al., 2005), the elimination of interviewer bias and data entry errors, and higher response rates (Howell and Smith, 2004).

There is still much to be ascertained about online surveys; however, they appear to be here to stay, given the movement away from mail surveys due to expense and telephone interviews due to changing technologies attractive to younger people. A large number of Generation Y'ers do not own a land-line telephone with a published number, and thus would not be included in the sample frame for land-line telephone interviews (Johnson, 2006).

Management at Farmers' Almanac TV made significant improvements to the website based on this survey, suggesting that organizations can easily garner low cost information from their clients/customers. The net benefits appear to be greatest for those organizations whose sampling frame is an existing customer email contact list.

\section{AUTHOR INFORMATION}

Jane Haas Philbrick, deceased, was Professor of Management, Savannah State University.

Ruth B. Smith is Associate Professor of Marketing, Savannah State University.

Barbara Bart, $\mathrm{PhD}$ is a financial consultant in Savannah, Georgia. 


\section{REFERENCES}

1. Berry, R.M. 2005. Web-based survey research: Lessons from the University of Akron study. Journal of Public Administration, 28: 57-72.

2. Burkey, J., \& Kuechler, W.L. 2003. Web-based surveys for corporate information gathering: A biasreducing design framework. IEEE Transactions on Professional Communication, 46(2), 81-93.

3. Comley, P. 2003. Innovation in online research - who needs online panels? MRS Research Conference Paper 36 as cited in Duffy, B., Smith, K., Terhanian, G., \& Bremer, J. Comparing data from online and face-to-face surveys. International Journal of Market Research, 47(6): 615-639.

4. Dillman, D.A. 2000. Mail and internet surveys: The tailored design method. New York: Wiley \& Sons.

5. Duffy, B., Smith, K., Terhanian, G., \& Bremer, J. 2005. Comparing data from online and face-to-face surveys. International Journal of Market Research, 47(6): 615-639.

6. $\quad$ Einhart, N. 2003. The opinion catcher. Business 2.0, 4(4): 87.

7. Foy, A. 2004. Conducting primary research online. The Marketing Review, 4:341-360.

8. Hanna, R.C., Weinberg, B., Dant, R.P., \& Berger, P.D. 2005. Do internet-based surveys increase personal self-disclosure? Database Marketing \& Customer Strategy Management, 12(4):342-356.

9. Healey, B., Macpherson, T., \& Kuijten, B. 2005. An empirical evaluation of three web survey design principles. Marketing Bulletin, 16 retrieved on September 7, 2006 from http://marketingbulletin.massey.ac.nz.

10. Heerewegh, D. 2005. Effects of personal salutations in e-mail invitations to participate in a web survey. Public Opinion Quarterly, 69(4):588-599.

11. Howell, C. and F.R. Smith (2004). Perceptions of the Relative Difficulty of the CPA and Bar Exams. The New Accountant, November,7-12.

12. Interactive Advertising Bureau. 2006. Internet advertising revenues close to \$4 billion for Q1 2006 retrieved on September 12, 2006 from http://www.iab.net/news/pr_2006_0530.asp.

13. Johnson, B. 2006, July 17. Forget phone and mail: Online's the best place to administer surveys. Advertising Age, 77(29): 23.

14. Meinert, D., Vitell, S.J., \& Blankenship, R. 1998 (Spring/Summer). Respondent "honesty": A comparison of computer versus paper and pencil questionnaire administration. The Journal of Marketing Management, 34-43.

15. McCullough, D. 1998. Web-based market research ushers in new age. Marketing News, 32(19):27-28.

16. Porter, S.R., \& Whitcomb, M.E. 2003. The impact of contract type on web survey response rates. Public Opinion Quarterly, 67(4): 579-588.

17. Roster, C.A., Rogers, R.D., Albaum, G., \& Klein, D. 2004. A comparison of response characteristics from web and telephone surveys. International Journal of Market Research, 46: 359-373.

18. Schaefer, D.R., \& Dillman, D.A. 1998. Development of standard e-mail methodology: Results of an experiment. Public Opinion Quarterly, 62(3): 378-397.

19. Schuldt, B.A., \& Trotten, J.W. 1994. Electronic mail versus mail survey response rates. Marketing Research, 6(1):36-39.

20. Shannon, D.M., \& Bradshaw, C.C. 2002. A comparison of response rate, response time, and costs of mail and electronic surveys. The Journal of Experimental Education, 70(2):179-192.

21. Sheehan, K. 2001. Email survey response rates: a review. Journal of Computer Mediated Communication, 6:2.

22. Sheehan, B., \& McMillan, J. 1999. Response variation in e-mail surveys: An exploration. Journal of Advertising Research, 39(4):5-54.

23. Truell, S.D. 2003. Use of internet tools for survey research. Information Technology, Learning, and Performance Journal, 21(1):31-38.

24. Weible, R., \& Wallace, J. 1998. Cyber research: The impact of the internet on data collection. Marketing Research, 10(3): 19-24. 